Hongyin Tao*, M. Rafael Salaberry, Meng Yeh and Alfred Rue Burch

\title{
Using authentic spoken language across all levels of language teaching: Developing discourse and interactional competence
}

https://doi.org/10.1515/caslar-2018-0001

\begin{abstract}
This journal issue contains a number of papers/teaching units that are dedicated to the review and analysis of some ways in which authentic language materials can be used for the teaching and learning of Mandarin Chinese from the beginning to advanced levels. We first describe the rationale for the expanded use of authentic language data in classroom instruction, and then we present four exploratory units to showcase some of the effective classroom teaching procedures that are useful to make learners aware of (and eventually use) important features of language interaction in Chinese. The units use two types of authentic materials: natural conversations and entertainment media (TV and movies). Some of the materials, due to the nature of the communicative settings associated with them, raise important theoretical questions about norms and expectations of (intercultural) communication and goals of language learning. This introduction provides a brief review of the theoretical foundations of the sample units and an overview of the units presented here.
\end{abstract}

Keywords: authentic language materials, Chinese language, classroom instruction

\section{Authentic language}

\subsection{Defining authentic language}

In a seminal paper published in 1972, Sandra Savignon discussed the value of shifting from a focus on language structure to a focus on communication strategies, thus providing impetus for what would become the Communicative

*Corresponding author: Hongyin Tao, Department of Asian Languages and Cultures, University of California, Los Angeles, CA 90095-1540, USA, E-mail: tao@humnet.ucla.edu

M. Rafael Salaberry: E-mail: salaberry@rice.edu, Meng Yeh: E-mail: myeh@rice.edu, Alfred Rue Burch: E-mail: arb18@rice.edu, Center for Languages \& Intercultural Communication, Rice University, Houston, TX 77005, USA 
Language Teaching (CLT) approach. In so doing, Savignon highlighted the importance of a sociolinguistic definition of language pointing out that the "[u]se of authentic language data has underscored the importance of context-setting, roles, genre, etc. in interpreting the meaning of a text." (1991: 270).

The definition of what constitutes authentic language data for L2 teaching is, however, a complex concept. Among the early descriptions of the construct, Morrow (1977: 13) states that: “An authentic text is a stretch of real language, produced by a real speaker or writer for a real audience and designed to convey a real message of some sort." Morrow's definition is in line with the concept of real world communicative competence as opposed to decontextualized descriptions of language prevalent among previous teaching approaches. Subsequent definitions emphasized the notion that authentic materials are generally understood to include language samples that are "not ... specifically produced for the purpose of language teaching” (Nunan 1989: 54).

Later elaborations on the concept of authenticity for L2 teaching touched on several dimensions that complexified the concept further: social, cultural and symbolic relations in the L2 (Kramsch 1998), the act of interpretation and appropriation of language samples in classroom use (van Lier 1996), and the notions of authentic versus genuine as represented in language corpora (Widdowson 1998). These additional factors have been incorporated into the integrated definition of the construct of authenticity of a language sample as complementary "criteria": provenance or authorship, communicative purpose, sociocultural context, learning activity and learners' perceptions.

\subsection{Authentic Chinese language data for teaching}

In the case of Chinese, as with the language acquisition field in general, there has been an increasing awareness of the importance of integrating authentic language data into language teaching and learning. A brief historical review of the field of Chinese language teaching will show a deeply rooted conviction of the relevance of authentic materials in effective language learning, and some interesting patterns of development can be seen to have emerged over the last half century or so.

In the early days of Chinese language pedagogical discourse, as reflected in the very first articles in the inaugural issue of the Journal of the Chinese Language Teachers Association published in 1966, DeFrancis and his contemporaries advocated to

[W]ean students away from textbookese and to start them in a more solid diet of real Chinese. It can begin at a very early stage, particularly if we provide students with close imitations of or slightly modified excerpts from actual publications. Such materials should 
be sharply distinguished from the kinds of watered-down rewriting which is so insipid that all taste of the original literary flavor is lost. (DeFrancis 1966: 17)

Clearly the major concerns of the forbearers had at that time were reading in authentic materials and developing literacy via the learning of Chinese characters.

With regard to authenticity in the spoken form, much attention has been paid to media production as something that represents some aspects of the spoken language. McGinnis (1990), for example, compared patterns of interrogatives as seen in Taiwanese drama and as taught in three major spoken Chinese textbooks. McGinnis shows that the patterns from these sources "differ greatly" and "in so many respects." Among others, he shows that native speakers tend to use about half of the ma-particle and A-not-A interrogatives due to interpersonal considerations other than information-inquiring interrogative functions. Also with attention to the media for spoken language features, Wang's (2005) teaching package, Tell it Like it Is! (Text with DVD) Natural Chinese for Advanced Learners, takes TV talk show productions from the Central China TV station as representing natural speech (for a review of this package, see Tao 2005b).

A major shift in conceptualization in CSL/CFL with regard to the spoken language and discourse competence is represented in Tao (2005a), where it is pointed out that most constructed spoken texts lack naturalistic contextual information, and as a result the language often appears to be unnatural. One of the solutions suggested by Tao (2005a) is to use context-based and contextoriented designs of teaching material to improve spoken Chinese language pedagogy. The major thrust of the paper is that mainstream colloquial Chinese teaching materials are devoid of contextual information, lack interactive strategies that enable learners to perform communicative tasks in real life situations, and focus on grammatical patterns that are distinct from what speakers actually use in discourse. To exemplify how naturalistic conversations can be used as teaching materials, Tao (2011) selected a set of natural conversations and developed ten units to illustrate how some of the commonly observed conversation patterns can be incorporated into actual classroom teaching. These features include conversational storytelling, co-participant reaction in talk-in-interaction, offering opinions and negotiating stance, and joint assessment of a state of affairs, among others.

The foregoing discussion, though very brief, shows that the long-lasting interest in integrating authentic materials in CSL/CFL has evolved from focusing mostly on the written language to spoken language, and from media language to spontaneous conversational language. However, with very few exceptions (see Meng 2008; Ning 2008), the type of materials developed so far have mostly been 
for the advanced learners. Thus, when presented with methods and samples of authentic materials for language teaching, many Chinese teachers doubt whether the same kind of methodology can be applied to lower level Chinese courses.

Indeed, the concerns expressed by many skeptical critics are real challenges for anyone who ventures to explore authentic materials for CSL/CFL language teaching. For example, one of the common problems is incorporating the teaching of discursive and interactional patterns into a regular classroom curriculum. A major obstacle here is that the standard classroom curriculum is very much vocabulary and grammar based, where tangible forms are the common objects of teaching and learning. Interactive patterns, on the other hand, evoke a different set of concepts beyond the lexical and grammatical constructs that are familiar to most teachers. There is a great deal of research (both in terms of material and method) required in elucidating discursive and interactive level patterns. Furthermore, even if discourse patterns are described, as many researchers have done, how they can be turned into practical, teachable units requires an additional investment of time dedicated to the designing and planning of such activities.

In the following sections we provide a summary of the theoretical rationales that inform the design of these teaching activities with authentic data, and we describe the teaching procedures that can be used to put those principles into practice. First, we present an overview of the two key theoretical concepts that serve as guiding principles for the four units: interactional competence and discourse and grammar. Then, we outline some relevant teaching frameworks (and related challenges) for the incorporation of authentic materials into language teaching practices. We finally offer a description of the organization of the units and their design considerations.

\section{Theoretical perspectives}

\subsection{Interactional competence}

The conceptualization of Communicative Competence, as it developed through the work of Hymes (1972), Canale and Swain (1980; Canale 1983), Bachman (1991; Bachman and Palmer 1996) and Celce-Murcia (2007; Celce-Murcia et al. 1995), has undergirded many of the innovations in foreign language pedagogy over the past four decades, especially with regards to Communicative Language Teaching (CLT) and Task Based Language Teaching (TBLT). In particular, the 
notion of Communicative Competence draws attention to sociolinguistic, pragmatic, and strategic competencies, highlighting that language use is dependent upon much more than the ability to string vocabulary together through grammatical constructions. It further highlighted, especially through TBLT (cf. Long 2015 inter alia) the important role that meaningful tasks based upon activities that learners would likely encounter in their lives has upon language acquisition. For all of these strengths, however, research on Communicative Competence maintained a focus on individual knowledge, rarely explicitly addressing that interaction "takes (at least) two to tango," often leaving the influence that interlocutors' contributions have over the learners' performance in interaction underspecified.

More recently, many researchers interested in exploring these underspecified aspects have done so under the rubric of Interactional Competence (IC). At the most fundamental level, IC refers to the practices (methods of conducting actions in interaction) and resources (linguistic, embodied and even material) that language users employ in order to achieve and maintain intersubjectivity, or mutual understanding (Hall and Pekarek-Doehler 2011; He and Young 1998). Furthermore, research on IC recognizes the inescapably contextualized and contingent nature of interaction, highlighting how any turn at talk is shaped by the talk that occurred prior, and further shaping subsequent talk. As such, IC is not viewed as knowledge an individual has, per se, but focuses more on the situated and contextualized accomplishment of actions through talk. Much IC literature has explored phenomena such as turn taking and repair (Lee 2006), storytelling in interaction (Pekarek-Doehler and Pochon-Berger 2015), and interactions in institutional or service settings (Nguyen 2012; Theodórsdóttir 2011), focusing on how language learners develop and expand their repertoires of interactional practices and resources fit to these contexts. The two IC-based teaching units presented in this issue, Yeh and $\mathrm{Fu}$, focus on the interactional practice of displaying recipiency, (i.e., reacting to prior talk in ways that show that the participant is listening and understanding the ongoing trajectory of the interaction) through the use of reactive tokens such as 对 'right', 哦 'oh', 是吗 'is that right?' and 很好 'good', which participants employ to a) take a pass on producing a longer turn at that point in the interaction, b) encourage their coparticipants to continue talking, and c) to display stances (how they think or feel) toward the prior talk. Though less IC-focused, Su and Tao's unit on 了 similarly shows how this particular resource is used in interaction to display stances toward prior talk or understandings.

Much of the research on IC has been conducted utilizing Conversation Analysis (CA; Hall etal. 2011; Kasper and Wagner 2011; see Young 2011; Taguchi 2015 for examples of research on IC from other methodological 
frameworks). CA focuses on the practices and resources employed by participants in talk-in-interaction (Schegloff 2007) through the fine-grained transcription of audio or video recordings of interactional data. Recent work that has applied CA and IC research findings to foreign language teaching (BarrajaRohan 2011; Betz and Huth 2014; Wong and Waring 2010) has utilized this focus on interactional detail, including timing (overlap, pauses, changes in speech tempo), intonation (rising or falling pitch) and volume, for creating pedagogical materials that draw learners' attention to the details of real-life talk-in-interaction, a practice followed by Yeh and $\mathrm{Fu}$ in this issue as well.

\subsection{Discourse and grammar}

Discourse and grammar encompasses a variety of functional linguistic approaches to language use (Cumming and Ono 1997), and in many respects its principles overlap with the notion of interactional competence as outlined in the preceding section. For example, Systemic Functional Grammar (SFG) as advocated by Michael Halliday emphasizes language as a network of systems, or interrelated sets of options for making meaning" (Halliday 1994: 15). According to this framework, part of the speaker's competence is the ability to make meaning by choosing different semiotic resources in text (Halliday 1977). This has direct implications for language teaching and learning. For example, when teaching a lexicogrammatical pattern (another term that figures prominently in SFG), the teacher must be aware of other options that are available in the language and subsequently make the learner aware of what it means to choose one form over another in interpersonal communication. Interactional linguistics, a recent development in discourse and grammar, emphasizes the inter-dependent relation of interaction and grammar: grammar is seen as part of the semiotic resources that speakers can deploy to accomplish actions (Ochs et al. 1996) and grammar can also be seen as emerging from language use, i.e. human interaction (Hopper 1998).

The two UCLA units touch upon these issues when discussing such issues as the choice between the final particle le and other forms, as well as the absence of the le form. Also, the notions of cohesion and coherence (Halliday and Hasan 1976) can play an important role in describing connected discourse and many lexicogrammatical forms that are typically out of the purview of formal grammar. For example, discourse connectives such as ranhou 'then, and', jieguo 'result, so' in conversation are extremely pervasive. However, these forms often link units whose domains go well beyond the typical word and phrase combinations; they are often used at junctures of higher-level discourse units 
such as speakers turns and narrative episodes. Both of the UCLA units examine lexicogrammatical units that require a view of grammar beyond the single sentence but instead at the discourse level in order to reach a proper understanding of the working of many linguistic units in Chinese.

The emphasis on interactional competence and the discourse basis of grammar is the direct consequence of the effect of previous studies on discourse analysis (DA). DA as a linguistic field has evolved from analyzing written text (e.g. Longacre 1983), to spoken narrative (e.g. Labov and Waletzky 1967; Chafe 1980), to the current emphasis on interaction and grammar (Ochs et al. 1996; Couper-Kuhlen and Selting To appear). All of these research traditions share a conviction, as discussed earlier, that linguistic competence goes far beyond single lexical items and isolated sentences.

\section{A new pedagogical framework for a new definition of language}

The broad definition of language prompted by CLT in the early 1990s started to shift the prevalence given to the written code to a more balanced perspective that paid attention to spoken language data as well. Savignon (1991: 264) noted that typical CLT activities encouraged students "to ask for information, to seek clarification, to use circumlocution and whatever other linguistic and nonlinguistic resources they could muster to negotiate meaning, to stick to the communicative task at hand ... " In hindsight, it is easy to see that the core of the teaching recommendations promoted by CLT did not provide much of a pedagogical framework; these recommendations were simply an extension of the definition of CLT. That is, the recommendations to incorporate "context and purpose" into the language classroom lacked a proper theoretical foundation focused on the acquisition through the use of authentic language data.

The lack of a pedagogical framework in the original proposal advanced by CLT is evident even today, four decades after the concept of CLT prompted the language teaching profession to use authentic data. Contrasting the teaching of the spoken and the written language, Gilmore (2007: 103), for instance, points out that

even when the model dialogues ARE accurate, material writers typically do not attempt to highlight key components of the generic structure. This contrasts notably with written genres where larger patterns, such as the introduction-main body-conclusion structure of discursive essays, are often pointed out. 
In essence, the transition from the concept of communicative competence (loosely described and circumscribed to the individual level) to the one based on interactional competence (interactionally-oriented and based on actual data from conversation analysis) does not necessarily entail that we have also addressed the acquisition/developmental processes that underline interactional communicative events. For instance, Pekarek-Doehler and Pochon-Berger (2015) document the case of a German speaking au pair learning French who deployed more varied interactional resources (i.e., "diversification of resources") in the context of storytelling events after just two months of a sojourn in the target language environment. The findings from Pekarek-Doehler and Pochon-Berger beg the question as to how a classroom environment may trigger a similar (albeit slower) process of diversification of resources.

To address the acquisition challenge identified in the previous paragraphs, the thematic articles in this volume provide detailed descriptions of how to put to pedagogical use the various conceptualizations of authentic data described in Section 2 above.

\subsection{UCLA units: Difficult grammatical constructions}

The two units developed by UCLA researchers, one on the final particle le and the other a well-known grammatical construction shi ... de, are designed with the following goals in mind. First, to showcase how the teaching and learning of some of the notoriously difficult grammar points can be facilitated with authentic materials and with a perspective of discourse interaction. In this regard, both le and shi ... de qualify as some of the most difficult grammar points in Chinese as a second language. As the papers show, almost every standard textbook has devoted some amounts of time and energy on them, and that there are literally hundreds of scholarly publications devoted to them, whether for linguistic research or for language pedagogy. Yet a commonly reported frustration from language instructors is that learners almost always encounter trouble in using (or not using) these constructions. Second, we would like to show that authentic materials can be effectively used at the lower level. As stated earlier, authentic materials are relatively commonly used at more advanced levels, especially for reading related tasks, yet rarely for listening and speaking at the lower levels. How to engage learners in authentic activities with limited vocabulary and grammar in a communicatively relevant and stimulating environment and at the same time addressing these universally acknowledged difficult items? We hope our units can show some of the ways in which pedagogical advancement can be made. Lastly, media entertainment productions as TV shows and movies 
have been a fascinating source of inspiration for teachers and learners alike, yet how these can be effectively exploited for lower level language instruction remains very much an underexplored area. An additional challenge is that while we strive to develop learners' interactive competence to engage in naturalistic communicative tasks, how the relatively artificial scenes and language of media production can be brought to bear on the interactive pragmatic goals we set for ourselves is a question we believe must be addressed and hopefully with robust results.

\subsection{Rice units: Response tokens in everyday and institutional conversation}

The two Rice units aim to develop students' interactional competence in displaying recipiency through the use of response tokens. To reach the goal, the units incorporate three main components: 1) using naturally occurring conversation; 2) utilizing research findings of CA; 3) adopting an inductive teaching methodology. It is critical to use natural conversation as teaching materials, since artificially contrived dialogues in textbook usually do not include recipients' response tokens. The CA-informed instruction leads students to analyze conversations line by line, discussing what action is displayed and how the action is achieved through the use of verbal or non-verbal resources. The activities are designed to guide students to notice and use response tokens in conversation. In a studentcentered guided-induction approach, students are led through scaffolded steps to examine language data and make generalizations about systematic patterns of language use. Thus, the units provide well-compiled samples of conversation data for students to explore and analyze the use of response tokens, an approach encouraging "an active, discovery-oriented approach on the part of the learners" (Fotos and Ellis 1999: 206). Yeh's teaching unit is designed for the beginning students. The teaching materials in the unit includes casual talks between L1 speakers, between learners, and between leaners and L1 speakers. Liang's unit focuses on doctor-patient conversation, part of the materials developed for intermediate-high students in the course "Chinese for Medical Professions."

\section{Conclusion}

In the preceding sections we provide a summary of the theoretical rationale that informs the design of teaching activities with authentic data, and we describe the teaching procedures that can be used to put those principles into 
practice. We hope that the four units we present here reflect the key theoretical concepts - interactional competence and the discourse basis of grammar - that inform what we believe to be new and exciting approaches to Chinese language pedagogy. As exploratory units, however, we further hope that this introduction and the teaching units will spark increased interest in pedagogical innovation amid the ever-ascending status of Chinese as a global language.

\section{References}

Bachman, Lyle. 1991. What does language testing have to offer? TESOL Quarterly 25(4). 671-704.

Bachman, Lyle \& Adrian Palmer. 1996. Language testing in practice: Designing and developing useful language tests (Vol. 1). Oxford: Oxford University Press.

Barraja-Rohan, Anne-Marie. 2011. Using conversation analysis in the second language classroom to teach interactional competence. Language Teaching Research 15(4). 479-507.

Betz, Emma M. \& Thorsten Huth. 2014. Beyond Grammar: Teaching Interaction in the German Language Classroom. Die Unterrichtspraxis/Teaching German 47(2). 140-163.

Canale, Michael. 1983. From communicative competence to communicative language pedagogy. Language and communication 1(1). 1-47.

Canale, Michael \& Merrill Swain. 1980. Theoretical bases of communicative approaches to second language teaching and testing. Applied linguistics 1(1). 1-47.

Celce-Murcia, Marianne. 2007. Rethinking the role of communicative competence in language teaching. In E.A. Soler \& M.P. Safont Jordà (eds.), Intercultural language use and language learning, 41-57. Dordrecht, The Netherlands: Springer.

Celce-Murcia, Marianne, Zoltan Dörnyei \& Sarah Thurrell. 1995. Communicative competence: A pedagogically motivated model with content specifications. Issues in Applied linguistics 6(2). 5-35.

Chafe, Wallace. 1980. The pear stories: Cognitive, cultural, and linguistic aspects of narrative production. Norwood, NJ: Ablex.

Couper-Kuhlen, Elizabeth \& Margret Selting. To appear. Interactional Linguistics: An introduction to language in social interaction. Cambridge: Cambridge University Press.

Cumming, Susana \& Tsuyoshi Ono. 1997. Discourse and Grammar. In Teun Van Dijk (ed.), Discourse as structure and process, 112-137. London: Sage Publications.

DeFrancis, John. 1966. Why Johnny can't read Chinese. Journal of the Chinese Language Teachers Association 1(1). 1-20.

Fotos, Sandra \& Rod Ellis. 1999. Communicating about grammar. In Rod Ellis (ed.), Learning a second language through interaction, 189-208. Amsterdam: John Benjamins Publishing Company.

Gilmore, Alex. 2007. Authentic materials and authenticity in foreign language teaching. Language Teaching 40. 97-118.

Hall, Joan Kelly, John Hellermann \& Simona Pekarek-Doehler (eds.). 2011. L2 interactional competence and development. Bristol, UK: Multilingual Matters. 
Hall, Joan Kelly \& Simona Pekarek-Doehler. 2011. L2 interactional competence and development. In Joan Kelly Hall, John Hellermann \& Simona Pekarek-Doehler (eds.), L2 interactional competence and development, 1-15. Bristol, UK: Multilingual Matters. Halliday, Michael A.K. 1977. Text as semantic choice in social context. In Teun A. Van Dijk \& János S. Petofi (eds.), Grammars and descriptions, 176-225. Berlin: Walter de Gruyter. Reprinted in M.A.K. Halliday, 2002. Linguistic Studies of Text and Discourse. Edited by J.J. Webster. London: Continuum.

Halliday, Michael A.K. 1994. Introduction to functional grammar, 2nd edn London: Edward Arnold.

Halliday, Michael A.K \& Ruqaiya Hasan. 1976. Cohesion in English. London: Longman.

He, Agnes Weiyun \& Richard Young. 1998. Language proficiency interviews: A discourse approach. In Richard Young \& Agnes Weiyun He (eds.), Talking and testing: Discourse approaches to the assessment of oral proficiency, 1-24. Amsterdam: John Benjamins.

Hopper, Paul, J. 1998. Emergent Grammar. In Michael Tomasello (ed.), The new psychology of language: Cognitive and functional approaches to language structure, 155-175. Mahwah, NJ: Lawrence Erlbaum.

Hymes, Dell. 1972. On communicative competence. In J. B. Pride \& J. Holmes (ed.), Sociolinguistics: Selected readings, 269-293. Harmondsworth: Penguin Books.

Kasper, Gabriele \& Johannes Wagner. 2011. A conversation-analytic approach to second language acquisition. In Dwight Atkinson (ed.), Alternative approaches to second language acquisition, 117-142. New York: Routledge.

Kramsch, Claire. 1998. Language and culture. Oxford: Oxford University Press.

Labov, William \& Joshua Waletzky. 1967. Narrative analysis: Oral versions of personal experience. In June Helm (ed.), Essays on the Verbal and Visual Arts, 12-44. Seattle: University of Washington Press.

Lee, Yo-An. 2006. Towards respecification of communicative competence: Condition of L2 instruction or its objective? Applied Linguistics 27(3). 349-376.

Long, Michael. 2015. Second language acquisition and task-based language teaching. Malden, MA: John Wiley \& Sons.

Longacre, Robert. 1983. The Grammar of discourse. New York: Springer.

McGinnis, Scott. 1990. A pragmatic analysis of Mandarin interrogatives: Data from modern Taiwan drama. Columbus, $\mathrm{OH}$ : The Ohio State University Doctoral dissertation.

Meng, Guo. 2008. Yuansheng Hanyu (Authentic spoken Chinese). Beijing: Peking University Press. 孟国. 2008. 《原声汉语-一初/中/高级实况听力教程》, 北京: 北京大学出版社。.

Morrow, Keith. 1977. Authentic texts and ESP. In Susan Holden (ed.), English for specific purposes, 13-17. London: Modern English Publications.

Nguyen, Hanh Thi. 2012. Developing interactional competence: A conversation-analytic study of patient consultations in pharmacy. Basingstoke, UK: Palgrave Macmillan.

Ning, Cynthia. 2008. Exploring in Chinese: A DVD-based course in intermediate Chinese. New Haven \& London: Yale University Press.

Nunan, David. 1989. Designing tasks for the communicative classroom. Cambridge: Cambridge University Press.

Ochs, Elinor, Emanuel A. Schegloff \& Sandra A. Thompson (eds.). 1996. Interaction and grammar. Cambridge: Cambridge University Press.

Pekarek-Doehler, Simona \& Evelyne Pochon-Berger. 2015. The development of L2 interactional competence: Evidence from turn-taking organization, sequence organization, repair organization and preference organization. In Teresa Cadierno 
\& Søren W. Eskildsen (eds.), Usage-based perspectives on second language learning, 233-270. Berlin: De Gruyter/Mouton.

Savignon, Sandra. 1972. Communicative competence: An experiment in foreign-language teaching. Philadelphia: The Center for Curriculum Development.

Savignon, Sandra. 1991. Communicative language teaching: State of the Art. TESOL Quarterly 25(2). 261-277.

Schegloff, Emmaneul A. 2007. Sequence organization in interaction: Volume 1: A primer in conversation analysis, vol. 1. Cambridge: Cambridge University Press.

Taguchi, Naoko. 2015. Developing interactional competence in a Japanese study abroad context. Bristol, UK: Multilingual Matters.

Tao, Hongyin. 2005a. The gap between natural speech and spoken Chinese teaching material: Toward a discourse approach to pedagogy. Journal of the Chinese Language Teachers Association 40(2). 1-24.

Tao, Hongyin. 2005b. Review of Tell It like It Is!. Journal of the Chinese Language Teachers Association 40(2). 117-125.

Tao, Hongyin. 2011. Working with spoken Chinese. State College, PA: Center for Advanced Language Proficiency Education and Research (CALPER) Publications, Pennsylvania State University.

Theodorsdottir, Guđrun. 2011. Second language interaction for business and learning. In Joan Kelly Hall, John Hellermann \& Simona Pekarek-Doehler (eds.), L2 interactional competence and development, 93-116. Bristol, UK: Multilingual Matters.

Van Lier, Leo. 1996. Interaction in the language classroom: Awareness, autonomy and authenticity. London: Longman.

Wang, Jianqi. 2005. Tell it like it is!: Natural Chinese for advanced learners. New Haven \& London: Yale University Press.

Widdowson, H.G. 1998. Context, community, and authentic language. TESOL Quarterly 32(4). 705-716.

Wong, Jean \& Hansun Z. Waring. 2010. Conversation analysis and second language pedagogy: A guide for ESL/EFL teachers. New York: Routledge.

Young, Richard F. 2011. Interactional competence in language learning, teaching, and testing. In E. Hinkel (ed.), Handbook of research in second language teaching and learning, vol. 2, 426-443. New York: Routledge.

\section{Bionotes}

\section{Hongyin Tao}

Hongyin Tao is Professor of Chinese language and linguistics and applied linguistics and coordinator of the Chinese language program at UCLA. His areas of expertise include Mandarin discourse and grammar, corpus linguistics, sociocultural linguistics, and applied linguistics. Some of his recent publications include Integrating Linguistics Research with Chinese Language Teaching and Learning (John Benjamin, 2016), Chinese under Globalization (World Scientific, 2011) and Working with Spoken Chinese (Penn State University, 2011). 


\section{Rafael Salaberry}

M. Rafael Salaberry (PhD, Cornell University) is a Professor of Second Language Acquisition in the Department of Spanish, Portuguese and Latin American Studies and he is also the Director of the Center for Languages and Intercultural Communication (CLIC) at Rice University. He has published several books with John Benjamins (2000, 2002, 2005), Georgetown University Press (2003, 2006), Continuum Press (2008), Multilingual Matters (2009), and Mouton de Gruyter (2014).

\section{Meng Yeh}

Meng Yeh, Teaching Professor at Rice, specializes in language pedagogy, curriculum design, and second language acquisition. Her recent research focuses on developing students' interactional, pragmatic and reading literacy competence. She co-authored two textbooks: Chaoyue: Advancing in Chinese (Princeton, 2010) and The Routledge Course in Modern Mandarin Chinese (Routledge, 2011). She served on the board for Chinese Language Teachers Association and as the Chair for SAT Chinese Committee, and is currently on AP Chinese Language and Culture Committee.

\section{Alfred Rue Burch}

Alfred Rue Burch is a postdoctoral fellow at Rice University. His research interests include (a) respecifying SLA topics such as motivation and communication strategies from a Conversation Analytic (CA) perspective, (b) language learning and use "in the wild," and (c) applying findings from this research to task based/supported language teaching. He has published in Language Learning and has co-edited a special issue on TBLT in TESOL Quarterly, and has co-authored chapters with Gabriele Kasper appearing in Talking Emotion in Multilingual Settings (Prior \& Kasper, 2016) and Authenticity, Language, and Interaction in Second Language Contexts (van Compernolle \& McGregor, 2016). 